\title{
HUBUNGAN TINGKAT PENGETAHUAN PERAWAT TENTANG BTCLS (Basic Trauma Cardiac Life Support) DENGAN PENANGANAN PRIMARY SURVEY DI IGD RSU YARSI PONTIANAK PROVINSI KALIMANTAN BARAT
}

\author{
Rina $^{1}$, Yunita Dwi Anggeini ${ }^{2}$, Nurul Amaliyah ${ }^{3}$ \\ ${ }^{1-2}$ STIKes Yarsi Pontianak, ${ }^{3}$ Poltekkes Kemenkes Pontianak
}

\author{
Rina : Program Studi Pendidikan Profesi Ners STIKes Yarsi Pontianak, \\ Jl. Panglima 'Aim No. 1 Pontianak Timur, Kalimantan Barat- 78232 \\ Email Rinarafa16@gmail.com
}

\begin{abstract}
ABSTRAK
Latar Belakang: IGD (Instalasi Gawat Darurat) merupakan salah satu unit Rumah Sakit yang dimana perawat memberikan tindakan keperawatan gawat darurat yang memerlukan penanganan Primary Survey terkait dalam pengetahuannya.

Tujuan: Penelitian ini bertujuan untuk mengetahui hubungan tingkat pengetahuan perawat tentang BTCLS (Basic Trauma Cardiac Life Support) dengan penanganan Primary Survey di IGD. Penelitian ini dilakukan di IGD RSU Yarsi Pontianak Provinsi Kalimantan Barat.

Metode: Penelitian ini merupakan jenis penelitian kuantitatif dengan metode analitik korelatif menggunakan desain cross sectional. Teknik pengambilan sampel dalam penelitian ini menggunakan teknik total sampling yaitu sebanyak 16 responden. Uji data statistik ini menggunakan uji Chi-Squere dengan program SPSS.

Hasil: Hasil penelitian menunjukan bahwa tingkat pengetahuan perawat dengan BTCLS $75 \%$ dengan kategori baik pada penanganan primary survey yang terampil dan $25 \%$ dengan kategori kurang dalam pengetahuan perawat tentang BTCLS dengan penanganan Primary Survey tidak terampil. Maka didapatkan nilai $\mathrm{p}$ value $=0,046$ ( $\mathrm{p}$ value $<0,05)$ sehingga dapat disimpulkan bahwa Ha diterima, yang artinya ada hubungan pengetahuan perawat tentang BTCLS dengan penanganan Primary Survey.

Kesimpulan: Tingkat pengetahuan perawat tentang Basic Trauma Cardiac Life Support ada berhubungan dengan penanganan Primary Survey. Sehingga rumah sakit secara umum dan instalasi gawat darurat pada khususnya diharapkan melakukan pelatihan, workshop dan seminar untuk meningkatkan ketempilan dan pengetahuan perawat dalam penanganan keperawatan gawat darurat .
\end{abstract}

Kata kunci : pengetahuan BTCLS, perawat, dan penanganan Primary Survey

ABSTRAC

Background: The Emergency Department is one of the hospital unit where nurses provide emergency nursing action that require handling Primary Survey related to rheir knowledge.

Objective: The aim of this research is to know the relationship between level of knowledge of nurses about BTCLS (Basic Trauma Cardiac Life Support) with the handling of the Primary Survey in the emergency department. The research conducted in the emergency departement Yarsi General Hospital in Pontianak West Kalimantan.

Method: The research used the quantitative with a correlative analytic, using cross sectional design. The samples of the research used a total sampling technique of sixteen respondents. The data of the research were analyzed by using the statistical analysis of Chi Square with the computer program of SPSS.

Result: The result of the research shows that $75 \%$ of the nurses have a good knowledge category with skilled Primary Survey handling, and the rest 25\% have a less knowledge category with skilled Primary Survey handling. The value of $p$ is 0,046 which is smaller than 0,05. This indicates that Ha is verifed meaning that there is not any correlation between the nurses' level of knowledge on BTCLS with the handling of the Primary Survey.

Conclusion: The level of nurses knowledge about BTCLS is related to the handling of the Primary Survey. Therefore, hospital in general and emergency installations in particular are expected to conduct training, woekshop and seminars to improve the skills and knowledge of nursing in handling of critical nursing emergency.

Keywords: BTCLS (Basic Trauma Cardiac Life Support), nurses, and Primary Survey handling. 


\section{PENDAHULUAN}

Instalasi Gawat Darurat (IGD) merupakan salah satu unit rumah sakit yang memberikan pelayanan gawat darurat untuk memenuhi kebutuhan pasien dalam kondisi gawat darurat dan harus segera mendapat penanganan darurat yang cepat dan tepat. Gawat suatu kondisi dimana pasien harus segera ditangani. Apabila tidak segera ditangani maka akan mengalami kecacatan atau kematian. Darurat suatu kondisi dimana pasien harus segera di tangani tetapi penundaan penanganan tidak akan menyebabkan kematian atau kecacatan (Jadmiko, 2014).

Kasus kematian dan kecacatan akibat pertolongan yang salah atau lambat pada pasien terutama di Instalasi Gawat Darurat (IGD) sering terjadi. IGD merupakan tempat yang dapat mencegah kematian dan kecacatan pada pasien, dan untuk mencapai tujuan tersebut, diperlukan suatu usaha tertentu agar hal ini terkait dengan fungsi IGD (Emergency, 2011).

\section{Menurut World Health Organization} (WHO) (2012) terdapat beberapa penyakit yang dianggap penyakit gawat darurat dan penyumbang kematian terbanyak di dunia diantaranya adalah penyakit jantung iskemik 7,4 juta (13,2\%), stroke 76,7 juta (11,9\%), penyakit paru obstruksi kronik 3,1 juta jiwa
(5,6\%), infeksi pernafasan bawah 3,1 juta $(5,5 \%)$, dan kanker 1,6 juta $(2,9 \%)$, kasus kecelakaan memberikan angka kematian mencapai 1,2 juta. Banyaknya pasien dengan kasus gawat darurat yang masuk kerumah sakit yang memerlukan pertolongan dengan segera agar tidak terjadinya kecacatan dan kematian. Kegawatan daruratan dari penyakit tersebut menjadi masalah seluruh dunia termasuk Negara-negara Asean.

Pada tahun 2007 data kunjungan pasien ke Instalasi Gawat Darurat (IGD) di seluruh Indonesia mencapai 4.402.205 (13,3\% dari total seluruh kunjungan di RSU) dengan jumlah kunjungan $12 \%$ dari kunjungan IGD. Jumlah yang signifikan ini kemudian memerlukan perhatian yang cukup besar dengan pelayanan pasien gawat darurat (Keputusan Menteri Kesehatan, 2009).

Menurut Kepmenkes tahun (2009) mengatur secara tertulis standarisasi penanganan instalasi gawatdarurat di rumah sakit menurut kelas RS, semakin besar kelas RS maka semakin lengkap sumber daya manusia dan peralatannya karena kasus pasien yang diterima semakin kompleks. Penanganan di Instalasi Gawat Darurat tidak menggunakan antrian tetapi dengan sistem triase yaitu melakukan pengkajian primer dan sekunder secara fokus, sistematis dan akurat. 
Keperawatan gawat darurat merupakan pelayanan keperawatan yang komperhensif di berikan kepada pasien dengan injuri akut atau sakit yang mengancam kehidupan. Sebagai seseorang spesialis perawat gawat darurat harus menghubungkan pengetahuan dan keterampilan untuk menangani respon pasien pada resusitasi, syok, trauma dan kegawatan yang mengancam jiwa lainnya, dan salah satu tempat untuk pasien gawat darurat adalah di Instalasi Gawat Darurat (IGD) (Krisanty et al, 2009).

Keperawatan gawat darurat menentukan peran, prilaku dan proses keperawatan yang melekat dalam praktik keperawatan yang menggambarkan karakteristik unik terhadap spesialisasi keperawatan gawat darurat. Praktik keperawatan gawat darurat merupakan proses yang sistematis meliputi proses keperawatan yang terdiri dari diagnosis keperawatan, pengambilan keputusan dan pemikiran analitis dan ilmiah serta investigasi (Kurniati, 2018).

Primary Survey merupakan pendekatan penanganan ke pasien sehingga pasien segera dapat diidentifikasi dan tertanggulangi dengan efektif. Pemeriksaan primary survey berdasarkan standar A-B-CD-E, dengan airway (A: jalan nafas), breahting (B: pernafasan), circulation (C: sirkulasi), disability (D: ketidakmampuan), exposure (E: penerapan) (Krisanty et al, 2009). Berdasarkan American Health Association (AHA, 2015) , RJP dilakukan dengan urutan C-A-B dimana penanganan sirkulasi menjadi fokus utama. Pengetahuan Primary Survey didapatkan perawat melalui pendidikan formal keperawatan sebagai salah satu bagian dari kurikulum pendidikan keperawatan dari jenjang SPK, Diploma III keperawatan, Diploma IV Keperawatan, maupun SI Keperawatan. Selain melalui pendidikan formal, pengetahuan dan kompetensi BLS juga dapat diperoleh melalui pelatihan-pelatihan BLS (Basic Life Support), diantaranya adalah pelatihan Penanganan Penderita Gawat Darurat (PPGD), Basic Cardio Life Support (BCLS), dan Basic Trauma Life Support (BTLS).

Dalam upaya menyelamatkan pasien dengan waktu yang singkat di Instalasi Gawat Darurat sangat diperlukan pengetahuan dan keterampilan petugas kesehatan. Hal ini berkaitan dengan pengambilan keputusan klinis agar tidak terjadi kesalahan. Pengetahuan perawat terkait ilmu yang mendasari tindakan dalam menangani pasien gawat darurat sangat penting, karena tindakan cepat dan akurat tergantung dari ilmu yang dikuasai oleh petugas kesehatan di 
Instalasi Gawat Darurat (Laoh \& Rako, 2014).

Pengetahuan dan keterampilan perawat sangat dibutuhkan, terutama dalam pengambilan keputusan klinis di IGD. Keterampilan perawat penting dalam penilaian awal untuk memprioritaskan perawatan pasien atas dasar pengambilan keputusan yang tepat. Untuk mendukung hal tersebut diperlukan pengetahuan dan keterampilan khusus dalam pemisahan jenis dan kegawatan pasien dalam triage, sehingga dalam penanganan pasien yang lebih optimal dan terarah (Oman, 2008).

Hasil penelitian Alhidayat (2013) dengan judul penelitian tentang hubungan tingkat pengetahuan terhadap tindakan Life Support ada hubungan yang bermakna antara pengetahuan pengkajian primer terhadap pelaksanaan tindakan Life Support, perawat dengan tingkat pengetahuan tentang pengkajian primer yang tinggi sangat berpengaruh terhadap pelaksanaan tindakan Life Support yang baik.

Hasil penelitian Jose Antonio (2017) dengan judul hubungan antara tingkat pengetahuan perawat tentang Initial Assesment dengan pelaksanaan Primary Survey di IGD, hasil menunjukan nilai korelasi yang positif hasil uji korelasi yang dilakukan, diketahui bahwa nilai signifikan yang ditunjukan ialah sebesar 0,000 atau $<0,05$ dengan nilai koefisien sebesar 0,743. Yang artinya bahwa semakin tinggi pengetahuan perawat tentang initial assesment semakin baik dalam pelaksanaan Primary Survey.

Hasil penelitian Karmila (2018) dengan judul hubungan pengetahuan perawat tentang Basic Life Support (BLS) dengan perilaku perawat dalam pelaksanaan Primary Survey di IGD, hasil menunjukan berdasarkan hasil uji chi-square hubungan antara pengetahuan perawat tentang Basic Life Support (BLS) dengan perilaku perawat dalam pelaksanaan Primary Survey, diketahui bahwa nilai signifikan $(\alpha)=0,05$ dan df $=1$ diperoleh hasil perhitungan $p$ $(0,028)<0,05$, maka Ho ditolak dan Ha diterima. Maka kesimpulannya ada hubungan antara pengetahuan perawat tentang Basic Life Support (BLS) dengan pelaksanaan Primary Survey.

Berdasarkan studi pendahuluan yang dilaksanakan oleh peneliti di IGD RSU Yarsi Pontianak, didapatkan data pasien yang datang di Rumah Sakit Umum Yarsi Pontianak Kalimantan Barat didapatkan bahwa jumlah pasien di IGD dalam 2 bulan pertama pada tahun 2019 (Januari-Februari) dengan jumlah 1.805 pasien, dengan pasien DOA ( Death On Arrival) 15 pasien 
diantaranya dengan pasien kegawatdaruratan yang membutuhkan penanganan Primary Survey.

Hasil wawancara dengan kepala ruangan Instalasi Gawat Darurat mengenai penanganan Primary Survey didapatkan data bahwa perawat disini telah mendapatkan pelatihan BLS (Basic Life Support), berupa pelatihan BTCLS (Basic Trauma Cardiac Life Support) dan PPGD (Penanganan Pertama Gawat Darurat), dimana pelatihan tersebut mampu mengatasi pasien dengan kegawatdaruratan. Dalam SOP penanganan Primary Survey di IGD masih menggunakan cara A-B-C untuk menangani pasien yang mengalami keadaan gawat darurat. Sedangkan dari hasil observasi tentang pengetahuan penanganan Primary Survey kepada tiga perawat dalam penanangan pasien gawatdarurat berbeda dengan pelatihan yang di lakukan dalam pelatihan BTCLS (Basic Trauma Cardiac Life Support). Pada saat dilakukan pemberian kuesioner untuk studi pendahuluan didapatkan hasil dari 4 perawat dalam tingkat pengetahuan dari $50 \%$ perawat hanya mampu menjawab pertanyaan sesuai dengan pengetahuan berdasarkan yang diketahuinya.

\section{METODE}

Penelitian ini menggunakan jenis penelitian kuantitatif dengan desain cross sectional yang dilaksanakan di Rumah Sakit Umum Yarsi Pontianak selama 1 bulan mulai dari pengumpulan data sampai analisis data. Populasi pada penelitian ini yaitu sebanyak 16 orang yang bekerja diruangan IGD RSU Yarsi Pontianak. Pengambilan sampel menggunakan teknik total sampling dengan kriteria inklusi : Perawat IGD yang bekerja di Rumah Sakit Umum Yarsi Pontianak, Perawat IGD yang memiliki sertifikat BTCLS. Penelitian menggunakan kuesioner sebanyak 25 item pertanyaan serta lembar observasi berdasarkan SOP dan pertanyaan yang telah diuji validitas dan reliabelitasnya. Sasaran responden yaitu perawat yang bekerja di IGD RSU Yarsi. Peneliti terlebih dahulu meminta persetujuan responden melalui inform consent yang telah di tandatangani kemudian kuesioner dibagikan untuk diisi oleh responden, setelah itu diinput menggunakan program computer dan diolah menggunakan software analisa statistik. Analisa data menggunakan uji Chi square. 


\section{HASIL}

A. Hasil Analisa Univariat dan Pembahasan Tabel 5.1 Distribusi Frekuensi Jenis Kelamin dengan (n) 16 Perawat IGD Tahun 2019

\begin{tabular}{lcc}
\hline Jenis Kelamin & F & $\%$ \\
\hline Laki-laki & 10 & 62.5 \\
Perempuan & 6 & 37.5 \\
Total & 16 & 100.0
\end{tabular}

Hasil penelitian yang telah dilakukan di IGD RSU Yarsi Pontianak yang berjumlah 16 responden didapatkan hasil dari tabel 5.1 bahwa sebagian besar perawat di IGD berjenis kelamin laki-laki berjumlah 10 orang $(62,5 \%)$ sedangkan untuk perempuan terdapat 6 orang $(37,5 \%)$. Dikarenakan dalam melakukan tindakan diruangan IGD memerlukan tenaga yang banyak misalnya dalam melakukan tindakan resusitasi pijat jantung memerlukan tenaga yang kuat dan maksimal untuk mencapai hasil yang baik. Namun dalam pelaksanaan menjalankan tugas tetap secara profesional sebagai perawat tanpa membedakan jenis kelamin. Hal ini dikemukakan Siagian (2004) yang menyatakan bahwa petugas kesehatan IGD berjenis kelamin laki-laki secara fisik lebih kuat dibandingkan perempuan, tetapi dalam hal pengetahuan dan penanganan Primary Survey tidak ada perbedaan dengan petugas kesehatan yang berjenis kelamin perempuan. Hal ini juga dikemukakan oleh Ramanda (2014) bahwa laki-laki dan perempuan memiliki perbedaan dalam komunikasi sosial dengan lingkungan sekitarnya sehingga menyebabkan pengetahuan yang dimiliki berbeda.

\section{Tabel 5.2 Distribusi Frekuensi Usia} dengan (n) 16

Perawat IGD Tahun 2019

\begin{tabular}{lll}
\hline Usia & F & $\%$ \\
\hline$<25$ tahun & 3 & 18.8
\end{tabular}

26-35 tahun

$13 \quad 81.2$

$\begin{array}{lll}\text { Total } & 16 & 100.0\end{array}$

Usia merupakan waktu pertumbuhan dan perkembangan seseorang individu. Kategori usia yang digunakan dalam penelitian ini adalah kategori menurut Depkes (2016) dimana usia <25 tahun termasuk kategori remaja akhir, usia antara 26-35 tahun termasuk dalam kategori dewasa awal. Berdasarkan hasil penelitian yang telah dilakukan peneliti hal ini menunjukan bahwa sebagian besar yang bekerja di IGD sebagian besar berusia antara 26-35 tahun yaitu merupakan dewasa awal di dalam area keperawatan gawat darurat dan kritis. Dimana diusia masa-masanya produktif untuk menciptakan hasil yang terbaik dalam 
skill maupun pengetahuan. Hal ini karena IGD membutuhkan perawat-perawat yang berpengalaman dan secara fisik masih muda serta mempunyai semangat muda, sehingga perawat yang belum berpengalaman mempunyai proporsi yang lebih sedikit. Dikarenakan IGD membutuhkan perawatperawat yang berpengalaman dan harus mempunyai pengetahuan yang memadai serta keterampilan yang profesional untuk memperoleh hasil yang baik. Usia mempunyai daya tangkap dan pola pikir seseorang. Semakin bertambah usia seseorang maka akan semakin berkembang daya tangkap dan pola pikirnya sehingga pengetahuan diperoleh akan semakin baik (Notoatmodjo, 2007). Berdasarkan kemenkes tahun 2006, bahwa kualifikasi tenaga kesehatan yang bekerja di IGD harus mempunyai pengetahuan yang memadai, mempunyai keterampilan yang sesuai.

Tabel 5.3 Distribusi Frekuensi Pendidikan dengan (n) 16 Perawat IGD Tahun 2019

\begin{tabular}{lll}
\hline Pendidikan & F & $\%$ \\
\hline DIII & 10 & 62.5 \\
SI & 1 & 6.2 \\
Ners & 5 & 31.2 \\
Total & 16 & 100.0 \\
\hline
\end{tabular}

Hasil penelitian yang telah dilakukan peneliti mendapatkan hasil sebagian besar responden mayoritas berpendidikan DIII Keperawatan
$(62,5 \%)$. Dengan tingkat pendidikan yang tinggi maka dapat mempengaruhi tingkat pengetahuan seseorang dalam berbagai hal. Pendidikan tinggi keperawatan Indonesia dimulai dari pendidikan jenjang Diploma tiga keperawatan (PPNI, 2003). Yang mendapatkan pengetahuan yang sama dengan jenjang S1 Keperawatan dalam pendokumentasian keperawatan. Hal ini sejalan dengan yang di ungkapkan oleh (Ellitan) 2003 dimana tingkat pendidikan yang semakin tinggi, dapat mencapai peningkatan harapan dalam hal karier dan memperoleh pengetahuan yang baik. Akan tetapi di sisi lain, dilapangan kerja yang tersedia tidak selalu sesuai dengan tingkat dan jenis pengetahuan serta keterampilan yang dimiliki oleh seseorang.

Pengetahuan juga bisa di dapatkan dalam penyelenggaraan pelatihan secara intensif dan terprogram untuk memiliki pengetahuan dan ketempilan yang baik tergantung dari sikap orang tersebut dalam memahami pengetahuan. Hal ini juga dapat disebabkan karena kurangnya integrasi antara pengetahuan yang didapat saat pendidikan dengan area klinik. Dalam pasal 1 butir $3 \mathrm{UU}$ No.23/1992 tentang kesehatan, dimana tenaga kesehatan adalah setiap orang yang mengabdikan diri dalam bidang kesehatan yang memiliki pengetahuan dan atau 
keterampilan melalui pendidikan kesehatan untuk melalukan upaya kesehatan.

Tabel 5.4 Distribusi Frekuensi Lamanya Bekerja dengan (n) 16 Perawat di IGD Tahun 2019

\begin{tabular}{lll}
\hline Lama Bekerja & $\mathrm{F}$ & $\%$ \\
\hline$<2$ tahun & 5 & 31.2 \\
2-5 tahun & 8 & 50.0 \\
6-10 tahun & 3 & 18.8 \\
Total & 16 & 100.0
\end{tabular}

Pekerjaan merupakan apa yang dapat membawa suatu pengalaman. Pengalaman belajar dalam bekerja yang dikembangkan memberikan pengetahuan dan keterampilan profesional serta pengalaman. Berdasarkan hasil penelitian yang telah dilakukan peneliti mendapatkan hasil pada tabel 5.4 adalah lama bekerja $<2$ tahun berjumlah 5 orang $(31,2 \%)$, 2-5 tahun berjumlah 8 orang (50\%), sedangkan responden yang lama berkerja selama 6-10 tahun berjumlah 3 orang $(18,8 \%)$. Lamanya bekerja berpengaruh positif terhadap kinerja perawat dalam penanganan Primary Survey. Hal ini sejalan dengan yang dikemukan oleh Mifta (2017) yang mengatakan lamanya bekerja berpengaruh positif terhadap kinerja karyawan. Lamanya bekerja dapat membawa suatu pengalaman dalam belajar yang dikembangkan untuk memberikan pengetahuan dan keterampilan profesional.
Lamanya bekerja memiliki dampak seseorang untuk mendapat pengalaman yang banyak. Seseorang yang memiliki pengalaman akan mempunyai pengetahuan yang baik bila dibandingkan dengan orang yang tidak memiliki pengalaman dalam segi apapun. Pengalaman dapat diperoleh dari diri sendiri maupun orang lain. Pengalaman akan mempengaruhi peningkatan pengetahuan seseorang karena semakin banyak seseorang mendengar, melihat dan melakukan tindakan tersebut, maka semakin bertambah pengetahuannya tentang subjek tersebut. Hal ini dilakukan dengan cara mengulang kembali pengalaman yang diperoleh untuk mengajarkan dirinya dalam memperbaiki kesalahan yang dihadapi masa lalu. Hal ini juga dikemukakan oleh Al-Ftlawy (2014) bahwa antara tingkat pengetahuan dan lama pengalaman mempunyai efek yang besar pada tingkat pengetahuan perawat dan perawat dapat mengembangkan pengetahuan mereka lewat pengalaman.

Tabel 5.5 Distribusi Frekuensi Tingkat Pengetahuan dengan (n) 16 Perawat di IGD Tahun 2019

\begin{tabular}{lll}
\hline Pengetahuan BTCLS & $\mathrm{F}$ & $\%$ \\
\hline Baik & 8 & 50.0 \\
Kurang & 8 & 50.0 \\
Total & 16 & 100.0
\end{tabular}


Berdasarkan hasil penelitian ini, dapat disimpulkan bahwa banyak faktor yang mempengaruhi pengetahuan perawat antara lain motivasi, dengan adanya motivasi baik dari dalam maupun luar dari diri sendiri dapat memacu seseorang dalam mengembangkan kemampuan dan kapasitas dirinya untuk mendapatkan hasil yang baik. Suatu yang dilihat seseorang dengan cara mendemonstrasikan belum tentu pengetahuannya kurang, sebaliknya orang yang memiliki pengetahuan yang baik belum tentu dalam melakukan tindakan benar, karena banyak faktor yang mempengaruhi seperti daya ingat seseorang dan cara pandang seseorang dalam memahami konsep teori. Hal ini juga dikemukakan oleh Meherali et al (2011) bahwa alasan dari rendahnya pengetahuan perawat dapat dikarenakan kurangnya integrasi pembelajaran konsep di area klinik. Pada dasarnya pengetahuan perawat merupakan aspek yang sangat penting. Pengetahuan perawat menentukan kualitas mereka dalam memberikan perawatan tentang pasien trauma dan cardiac, khususnya untuk pencegahan terjadinya cedera.
Tabel 5.6 Distribusi $\quad$ Frekuensi Penanganan Primary Survey dengan (n) 16 Perawat di IGD Tahun 2019

\begin{tabular}{lcc}
\hline $\begin{array}{l}\text { Penanganan } \\
\text { Primary } \\
\text { Survey }\end{array}$ & F & $\%$ \\
\hline $\begin{array}{l}\text { Terampil } \\
\text { tidak } \\
\text { terampil }\end{array}$ & 8 & 50.0 \\
Total & 8 & 50.0 \\
\hline
\end{tabular}

Primary Survey adalah mengatur pendekatan kepasien sehingga pasien segera dapat diidentifikasi dan ditanggulangi dengan efektif (Krisanty et al, 2009). Dalam penelitian ini perawat yang memiliki keterampilan dalam melaksanakan penanganan primary survey dalam kategori terampil berjumlah 8 orang $(50 \%)$ sedangkan tidak terampil berjumlah 8 orang $(50 \%)$. Keterampilan seseorang merupakan perkembangan individu, karena faktor pengalaman individu mempunyai peranan penting dalam tindakan penanganan Primary Survey. Hal ini sesuai dengan kejadian dilapangan yang diperoleh oleh peneliti, sebagian besar perawat yang bekerja di IGD dengan tingkat pendidikan DIII berjumlah 10 orang $(62,5 \%)$. Dikarena perawat DIII merupakan perawat vocasional atau perawat yang terampil artinya ketika seorang perawat DIII mendapatkan teori dari pembelajaran 
mereka akan langsung turun kelapangan untuk praktek ke pasien. Akan tetapi dalam mendokumentasikan keperawatan DIII dan S1 tidak ada bedanya. Pengalaman yang mendalam akan menentukan keberhasilan dalam melakukan tindakan keperawatan gawat darurat untuk menolong pasien dengan gawat darurat. Hal ini dikemukakan oleh Mancini (2011) dimana penanganan Primary Survey pada pasien gawat darurat penting dilakukan secara efektif dan efisien. Karena dalam penanganan primary survey memerlukan tempo waktu yang singkat, karena apabila terjadi kekurangan oksigen dalam waktu 6-8 menit dapat menyebabkan kerusakan otak permanen, lebih dari 10 menit akan menyebabkan kematian.

B. Analisa Bivariat dan Pembahasan

Tabel 5.7 Hubungan pengetahuan perawat tentang BTCLS (Basic Trauma Cardiac Life Suport) dengan penanganan Primary Survey di IGD 2019

\begin{tabular}{cccccccc}
\hline \multicolumn{7}{c}{ Penanganan Primary Survey } \\
\hline & & \multicolumn{7}{c}{ Terampil } & Tidak & Nilai & Nilai P \\
& & & Terampil & OR & \\
\hline \multirow{3}{*}{$\begin{array}{c}\text { Pengetahuan } \\
\text { BTCLS }\end{array}$} & Baik & 6 & 75 & 2 & 25 & 9,000 & 0,046 \\
& Kurang & 2 & 25 & 6 & 75 & & \\
& Total & 8 & 50 & 8 & 50 & & \\
\hline
\end{tabular}

Dari hasil analisa bivariat diperoleh bahwa ada hubungan antara tingkat pengetahuan perawat tentang Basic Trauma Cardiac Life Support dengan penanganan Primary Survey dengan nilai $\alpha=0,046$. Hal ini sejalan dengan yang diungkapkan oleh Jose (2017) bahwa ada hubungan pengetahuan dengan penanganan Primary Survey. Karena semakin tinggi pengetahuan perawat maka semakin baik pula dalam melakukan penanganan Primary Survey.

Berdasarkan pernyataan di atas dapat diambil kesimpulan bahwa dengan tingkat pengetahuan yang baik mampu mengaplikasikan penanganan Primary Survey secara terampil. Pernyataan ini dilihat dari uji chi-square pada tabel 5.7 dengan tabel silang pada kategori baik (75\%) akan tetapi terjadi kecenderungan dengan hasil (25\%) perawat tidak terampil. Dalam penelitian ini perawat dengan tingkat pengetahuan kurang juga memiliki tingkat keterampilan dalam penanganan Primary Survey (25\%). Hal ini terjadi banyak faktor yang mempengaruhi dalam penanganan Primary Survey yang berhubungan dengan tingkat pengetahuan. Bisa dikarenakan pelatihan BTCLS (Basic Trauma Cardiac Life Support) yang pernah dilakukannya sudah lama karena sertifikat tersebut berlaku hanya lima tahun saja, sehingga 
menyebabkan banyak perawat lupa atau tidak ingat dalam tindakan penanangan Primary Survey dengan pasien trauma dan cardiac, hal tersebut bearti bahwa perawat tidak mempunyai kesempatan yang tinggi untuk mengembangkan pengetahuan mereka melalui sesi pelatihan. Akan tetapi sebagian besar pengetahuan dalam penanganan Primary Survey dapat diperoleh dari informasi dalam membaca buku keperawatan terbaru atau mendapat informasi dari rekanrekan perawat.

Tingkat kemampuan dan pengetahuan seseorang tidak bisa diketahui karena berasal dari diri sendiri, dalam bekerja diperlukan keterampilan dan kemampuan berfikir yang luas. Setiap individu akan memiliki tingkat cara pandang yang berbeda dalam penanganan Primary Survey, hal ini sependapat yang dikemukakan oleh Hasibuan (2010). Skill atau keterampilan seseorang dapat dilihat saat perawat melakukan tindakan keperawatan sesuai dengan SOP (standar prosedur operasional) yang berlaku. Primary Survey juga dipengaruhi oleh beberapa faktor seperti pelatihan atau workshop yang diadakan di rumah sakit untuk lebih memahami dan berpotensi dalam melakukan tindakan. Perawat yang lebih sering mengikuti pelatihan secara langsung akan lebih memahami prosedur penanganan primary survey. Hal ini juga dikemukakan Lontoh (2013) sebagian besar dimana adanya peningkatan pengetahuan sesudah diberikan pelatihan. Primary Survey merupakan tindakan yang memerlukan waktu cepat untuk mengidentifikasi dan memperbaiki masalah yang mengancam kehidupan. Usia, Pendidikan dan lamanya bekerja seorang perawat juga berpengaruh pada pengetahuan perawat tersebut tentang penanganan Primary Survey. Karena usia mempengaruhi daya tangkap dan pola pikir seseorang. Semakin bertambah usia seseorang maka akan semakin berkembang daya tangkap dan pola pikirnya sehingga pengetahuan diperoleh akan semakin baik. Pengalaman kerja merupakan salah satu faktor yang berpengaruh terhadap pengetahuan perawat. Hal ini juga dikemukakan Innayatullah (2014) dimana pengalaman perawat bekerja berpengaruh terhadap pengetahuan perawat. Hal tersebut terjadi karena semakin lama perawat bekerja, maka semakin banyak kasus yang ditanganinya sehingga semakin meningkat pengetahuan dan pengalaman yang didapatkan.

\section{KESIMPULAN}

1. Berdasarkan karakteristik responden perawat yang bekerja di IGD dengan kategori usia 26-35 lebih besar dari <25 dengan $(81,2 \%)$. Perawat yang bekerja di 
IGD dengan jenjang pendidikan sebagian lebih besar DIII dibandingan dengan SI dan Ners dengan (62,5\%). Lama bekerjanya perawat di IGD dengan lamanya 2-5 tahun (50\%) dibandingkan dengan yang bekerja selama $<2$ tahun $(31,2 \%)$ dan 6-10 tahun $(18,8 \%)$.

2. Tingkat pengetahuan perawat tentang BTCLS (Basic Trauma Cardiac Life Support) dengan kategori baik berjumlah 8 orang dengan (50\%), kurang berjumlah 8 orang dengan $(50 \%)$.

3. Penanganan Primary Survey dengan kategori terampil berjumlah 8 orang (50\%) dan tidak terampil berjumlah 8 orang $(50 \%)$.

4. Terdapat ada hubungan tingkat pengetahuan tentang BTCLS (Basic Trauma Cardiac Life Support) dengan penanganan Primary Survey di IGD RSU Yarsi Pontianak Provinsi Kalimantan Barat karena nilai $\alpha=0,046$ dikarena nilai p valuenya lebih kecil dari 0,05.

\section{DAFTAR PUSTAKA}

Alhidayat, N,A., Rahmat, A., Simunati. (2013). Hubungan Tingkat Pengetahuan Perawat Instalasi Gawat Darurat tentang Pengkajian terhadap Pelaksanaan Tindakan Life Support di Rumah Sakit Pelamonia Makassar. Vol. 2, No. 4.
Al-Ftlawy DMH. (2014). Determination of nurses'knowledge toward care provided to patients wite acute myocardial infarction in Al-Najaf City.Iraq academic Scientific Journals. American Heart Association (AHA). (2010). Pediatric Basic Life Support : Guidelines for Cardiopulmonary Resuscitation and Emergency Cardiovascular Care.

Emergency, P. (2011). Basic Trauma Life Support (BTCLS). Bogor : PT. Pro Emergency.

Hasibuan. (2010). Manajemen Sumber Daya Manusia. Jakarta: Bumi Aksara.

Inayatullah I. (2014). Hubungan Tingkat Pendidikan dengan Tingkat Pengetahuan Perawat tentang Asuhan Keperawatan dengan Pedoman NANDA NOC dan NIC di Rumah Sakit Umum Daerah Ajibarang. Jadmiko, Arief W. (2017). Pengetahuan Dan Kecerdasan Emosional Terhadap Manajemen Nyeri Di Instalasi Gawat Darurat. Surakarta: Program Studi Ilmu Keperawatan Universitas Muhammadiyah Surakarta. Jurnal Riset Kesehatan.

Keputusan Menteri Kesehatan Republik Indonesia. (2009). Standar Instalasi 
Gawat Darurat (IGD) Rumah Sakit. Jakarta : Menteri Kesehatan Republik Indonesia.

Krisanty, P., Manurung, S., Wartonah, D., Suratun, Sumartini, M. (2009). Asuhan Keperawatan Gawat Darurat. Trans Info Media : Jakarta.

Mifta Septarina. (2017). Pengaruh Tingkat Pendidikan dan Lamanya Bekerja Terhadap Kinerja Karyawan. Palembang.

Notoatmodjo, S. (2010). Metodologi Penelitian Kesehatan. Rineka Cipta : Jakarta.

Oman, Kathleen S. (2008). Panduan Belajar Keperawatan Emergensi. Jakarta : EGC.

PPNI. (2003). Standar Profesi dan Kode Etik Perawat Indonesia. Jakarta: PPNI.

Ramanda FA, Waluyo A. (2014). Gambaran Tingkat Pengetahuan Perawat terhadap HIV.

Yayasan Ambulans Gawat Darurat 118. (2015). Basic trauma life support and basic cardiac life support [edisi 7.]. Jakarta: Ambulan Gawat Darurat 118. 